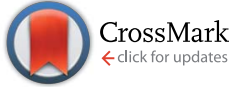

Cite this: RSC Adv., 2015, 5, 83122
Received 3rd July 2015

Accepted 24th September 2015

DOI: $10.1039 / \mathrm{c} 5 \mathrm{ra12963j}$

www.rsc.org/advances

\section{Hole-transporting side-chain polystyrenes based on TCTA with tuned glass transition and optimized electronic properties $\uparrow$}

\author{
Felix R. P. Limberg, ${ }^{a}$ Arunas Miasojedovas, ${ }^{b}$ Patrick Pingel, ${ }^{a}$ Felix Reisbeck, ${ }^{a}$ \\ Silvia Janietz, ${ }^{a}$ Andrew P. Monkman ${ }^{\mathrm{b}}$ and Hartmut Krüger ${ }^{\star a}$
}

\begin{abstract}
The development of crosslinkable materials for the fabrication of solution processable OLEDs presents challenges, especially regarding the adjustment of the glass transition $\left(T_{\mathrm{g}}\right)$, which has a significant influence on crosslinking kinetics and device life-time. Crosslinkable hole transport materials based on poly(N,N-bis(4-(9H-carbazol-9-yl)phenyl)-4-vinylaniline) (poly-TCTA) with covalently attached plasticizers for $T_{\mathrm{g}}$ control and azide functionalities for azide-alkyne crosslinking are presented. These polymers have an optimal $T_{\mathrm{g}}$ of around $150{ }^{\circ} \mathrm{C}$ and show superior crosslinking performances and solution resistibilities. Incorporation of electron-pushing alkoxides to the pendant groups combines the $T_{\mathrm{g}}$ adjustment approach with a systematic tuning of the $\mathrm{HOMO}$ level from -5.7 to $-5.3 \mathrm{eV}$. All presented polymers have good charge transport and injection properties and are ideal for applications in phosphorescent OLEDs due to their high triplet energies $(>2.8 \mathrm{eV})$. The new crosslinkable poly-TCTAbased materials are applied as hole-transport layers (HTLs) in fully solution-processed OLEDs. An improvement of the device performance is demonstrated for OLEDs with additional crosslinked HTL.
\end{abstract}

\section{Introduction}

Modern organic light-emitting diodes (OLEDs) consist of several different functional materials and layers with welldefined thicknesses and morphologies. In order to realize such multi-layer structures, most OLEDs are still based on small molecules which often need to be processed under high-cost vacuum conditions. Therefore, their use is still limited to expensive high-resolution display applications, in, e.g., cellphones and televisions, and to rare examples of expensive lighting applications. ${ }^{1,2}$ As an alternative, solution-based processes enable high throughput and low-cost fabrication of OLEDs on large size. However, solvent-processing of organic multi-layers is still difficult; e.g., controlling de-wetting, crystallization, or re-dissolving of deposited layers is a challenge. Orthogonal solvent strategies ${ }^{3}$ or stamping techniques ${ }^{4}$ can circumvent these problems but put severe constraints on the choice of compatible materials, number of layers, or solvents. Crosslinking techniques are a feasible alternative towards fully solution-processed multi-layer OLEDs and may enable low-cost lighting applications. ${ }^{5}$

${ }^{a}$ Fraunhofer Institute for Applied Polymer Research, Wissenschaftspark Golm, Geiselbergstr. 69, D-14476 Potsdam, Germany. E-mail: hartmut.krueger@iap. fraunhofer.de

${ }^{b}$ Physics Department, University of Durham, South Road, Durham DH1 3LE, UK

$\dagger$ Electronic supplementary information (ESI) available. See DOI: $10.1039 / \mathrm{c} 5 \mathrm{ra} 12963 \mathrm{j}$
Crosslinking of organic layers generally requires exposure of the sample to UV light, to elevated temperatures, or to both in order to activate and promote the crosslinking reaction. ${ }^{5}$ Thereby, completion of the reaction can only be reached, if the sample is heated above the glass transition or melting temperature, at least once in a final curing step. ${ }^{6}$ Below the glass transition, the crosslinker groups are "frozen" in the glassy state and hence their reaction is restricted. For an economical and gentle processing, the glass transition temperature of a crosslinkable material should be as low as possible; however, a strong correlation between a high glass transition $\left(T_{\mathrm{g}}\right)$, morphological stability of organic layers, and long OLED lifetimes is apparent. ${ }^{7}$ In order to meet both processing and lifetime demands, we believe that a moderate glass transition, i.e., a moderate crosslinking temperature, between $150{ }^{\circ} \mathrm{C}$ and 170 ${ }^{\circ} \mathrm{C}$ would be ideal.

Recently, we introduced poly $(N, N$-bis(4-(9H-carbazol-9-yl) phenyl)-4-vinylaniline) (poly-TCTA) as host material in green phosphorescent OLEDs. ${ }^{8}$ In this polymer, a tris(4-(9H-carbazol9-yl)phenyl)amine (TCTA) analogue is bound as pendant group to a polystyrene backbone. Polystyrene-based side chain functionalized polymers are known for excellent film formation and the morphological stability of such layers.,10 Good holetransporting properties and the high triplet energy $(2.8 \mathrm{eV})$ of poly-TCTA led to good overall electroluminescent performances. Further device optimization might be possible by introducing a hole transport layer (HTL) between anode and the emission layer. The HTL material should possess a HOMO 
energy that compensates for the energy offset of the anode's work function (PEDOT:PSS $\approx 5.0 \mathrm{eV})^{11}$ and the polymer's HOMO-derived hole transport states (e.g., poly-TCTA, $-5.6 \mathrm{eV}$ ) in order to improve charge carrier injection and to reduce the driving voltage. The HTL may also serve as an electron blocking layer.

Liaptsis and Meerholz introduced electron-pushing or -pulling groups to the aromatic core of a crosslinkable derivative of the hole-transporting small molecule 1-bis[4-[N,N-di(4-tolyl) amino]phenyl]cyclohexane (TAPC). ${ }^{12}$ This allowed for a systematic variation of the HOMO energy of these compounds and, in turn, led to tunability of the hole injection barrier in their OLED devices. In our work, we follow similar approaches to modify the chemical structure, electrooptical, and physical properties of poly-TCTA towards its applicability as crosslinked HTL.

Here, we present strategies to reduce the relatively high glass transition $\left(247^{\circ} \mathrm{C}\right)$ of side-chain poly-TCTA by either introducing plasticizers as co-monomers into the polymer chain or by attaching flexible substituents directly at the functional sidechain units. The glass transition $\left(T_{\mathrm{g}}\right)$ can be tuned in a broad range. The latter approach has been extended towards the use of electron pushing substituents which provides a systematical tunability of the HOMO level. The crosslinkable new HTL polymers are applied in OLED stacks.

\section{Results and discussion}

In general, the $T_{\mathrm{g}}$ of polymers can be reduced by a variety of commercially available plasticizers. However, their application in OLEDs is strongly limited, because they must meet the following criteria: (1) miscibility with the host; (2) chemical and optical inertness; (3) no diffusion into adjacent layers (therefore, a covalently bond plasticizer would be favorable); (4) no detrimental interference with charge transport or light emissive materials.

\section{$T_{\mathrm{g}}$ control by covalently attached plasticizers}

The first straight forward approach is the covalent attachment of a plasticizer as a co-monomer into the polymer (Scheme 1). The homo-polymer of 1-decyl-4-vinylbenzene (P) has a very deep $T_{\mathrm{g}}$ of about $-65{ }^{\circ} \mathrm{C}$, the lowest reported $T_{\mathrm{g}}$ of $p$-alkylstyrenes, ${ }^{13}$ which makes this compound a strong plasticizer. In addition,

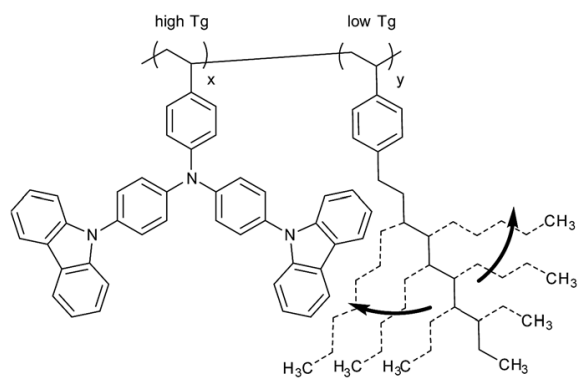

Scheme 1 Copolymeric $T_{\mathrm{g}}$ reduction approach using 1-decyl-4vinylbenzene as plasticizer $(\mathrm{P})$. the plasticizer is not conjugated and is therefore expected to have no influence on the optical properties which are determined by the TCTA units.

1-Decyl-4-vinylbenzene (P) was copolymerized with monoTCTA (2a); the $\mathbf{P}$ feed ratios are $25 \mathrm{M} \%$ (12 wt\%) for polymer $3 \mathbf{a}_{25}, 50 \mathrm{M} \%$ (29 wt\%) for $\mathbf{3} \mathbf{a}_{50}$, and $75 \mathrm{M} \%$ (55 wt\%) for $\mathbf{3} \mathbf{a}_{75}$ (Scheme 2). With increasing amount of plasticizer the numberaverage molecular weight $\left(M_{\mathrm{n}}\right)$ is only slightly decreased, whereas the weight-average molecular weight $\left(M_{\mathrm{w}}\right)$ decreases significantly accompanied by lower polydispersities (PDI) of the copolymers. This can be explained by the reduced average monomer weight at higher plasticizer content. The amount of $\mathbf{P}$ in the copolymers, determined with ${ }^{1} \mathrm{H}-\mathrm{NMR}$, is in good agreement with the feed ratios. Selected properties of the prepared polymer samples are summarized in Tables 1 and 2.

A strong $T_{\mathrm{g}}$ decrease was observed with increasing amounts of plasticizer $\mathbf{P}$ as expected. This decrease shows a linear dependence between the measured glass transition and the weight percentage of $\mathbf{P}$ (Fig. 1), wherein $3 \mathbf{a}_{50}\left(T_{\mathrm{g}}=162{ }^{\circ} \mathrm{C}\right)$ is in the desired $T_{\mathrm{g}}$-range for OLED fabrication, while $\mathbf{3} \mathbf{a}_{25}\left(T_{\mathrm{g}}=\right.$ $\left.203{ }^{\circ} \mathrm{C}\right)$ and $3 \mathbf{a}_{75}\left(T_{\mathrm{g}}=87.2{ }^{\circ} \mathrm{C}\right)$ are outside of it. Additionally, the plasticizer leads to an improved solubility in common solvents.

Note that the introduction of the plasticizer leads to no significant changes of the HOMO and LUMO levels of the polymers (see Table 2). However, the electrical hole current in unipolar diodes (not shown) is considerably impaired for those polymers as compared to the currents in polymer layers without plasticizer. This may be due to the insulating nature of the decylbenzene moieties.

\section{Crosslinking of low- and high- $T_{\mathrm{g}}$ polymers}

In order to demonstrate that the glass transition affects the crosslinking kinetics strongly, 1-(azidomethyl)-4-vinylbenzene and monomer $\mathbf{2 a}$ were copolymerized either with or without additional plasticizer $\mathbf{P}$ to give a crosslinkable low- $\left(\mathbf{3 a}_{\mathbf{4 3}} \mathbf{A} \mathbf{Z}_{\mathbf{1 5}}\right)$ and high- $T_{\mathrm{g}}\left(\mathbf{3 a A Z}_{\mathbf{1 5}}\right)$ polymer with $15 \mathrm{M} \%$ azide content, respectively (Scheme 3 ). Crosslinking can be performed thermally after adding 4,4'-(propane-2,2-diyl)bis((prop-2-yn-1-yloxy)benzene) (XL).

Crosslinking of copolymerized azides and alkynes in polystyrenes via triazole formation has initially been described by Spruell et al. ${ }^{\mathbf{1 4}}$ The introduction of bis-alkyne (XL) as separate crosslinker component has the advantage of an improved bench-stability of the resulting materials. The thermal range of crosslinking can be between $150{ }^{\circ} \mathrm{C}$, where the cycloaddition of azides and alkynes starts, and $200{ }^{\circ} \mathrm{C}$, where unwanted thermal

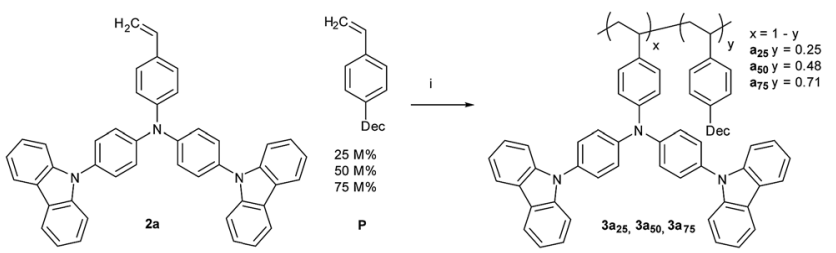

Scheme 2 Synthetic route towards $T_{\mathrm{g}}$ adapted poly-TCTA copolymers with 1-decyl-4-vinylbenzene (P) as comonomer. 
Table 1 Polymer synthesis yields, molecular weight distributions, and glass transitions

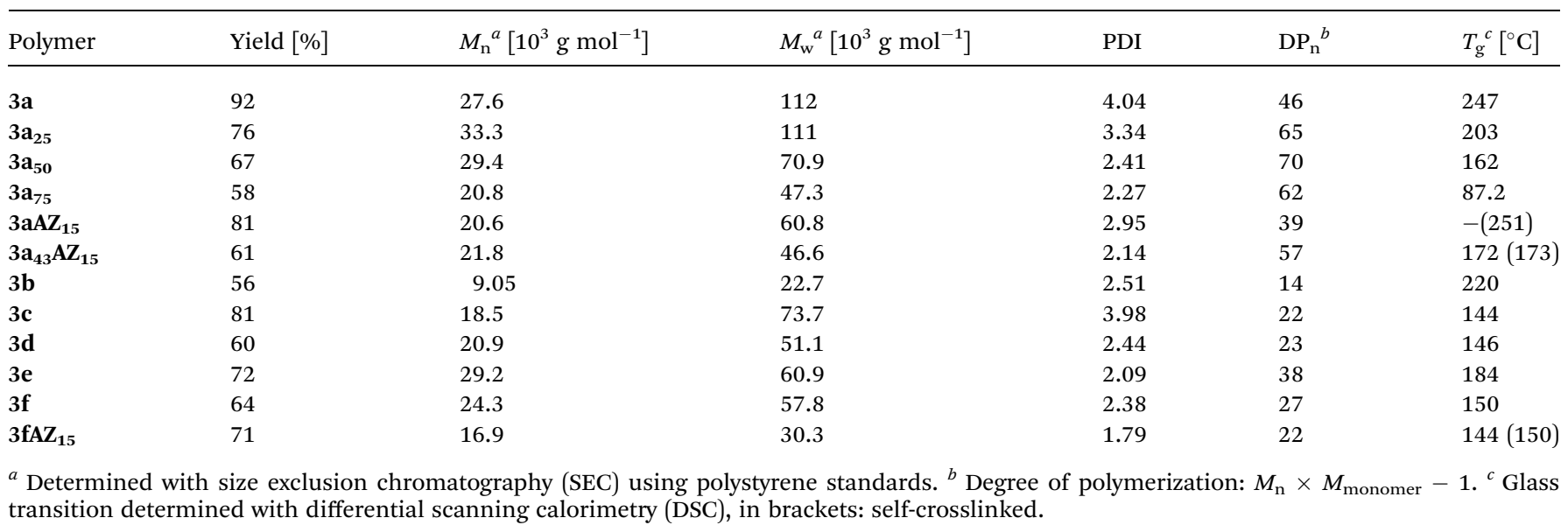

decomposition of the azides and nitrene formation set in. Formed nitrenes can then easily insert into aliphatic and aromatic bonds with detrimental effects on the charge transport in conjugated materials. ${ }^{15}$

Azide decomposition is visible as an exothermic reaction in differential scanning calorimetry (DSC) spectra of neat $\mathbf{3 a A Z}_{\mathbf{1 5}}$ and $3_{43} \mathbf{A Z}_{15}$ at around $250{ }^{\circ} \mathrm{C}$ (Fig. S1 and $\mathrm{S} 2 \dagger$ ). The glass transitions of both polymers are visible in the subsequent DSC cycle at $250{ }^{\circ} \mathrm{C}$ and $172{ }^{\circ} \mathrm{C}$, respectively. The reduced $T_{g}$ of $\mathbf{3 a}_{43} \mathbf{A Z}_{15}$ is clearly due to the incorporation of the plasticizer. Addition of the crosslinker $\mathbf{X L}$ to $\mathbf{3 a A Z}_{\mathbf{1 5}}$ and $\mathbf{3 a}_{\mathbf{4 3}} \mathbf{A} \mathbf{Z}_{\mathbf{1 5}}$ leads to an exothermic DSC peak above $150{ }^{\circ} \mathrm{C}$ which can be ascribed to the desired azide-alkyne cycloaddition. After the cycloaddition, the $T_{\mathrm{g}} \mathrm{s}$ of the crosslinked polymers are further reduced to $240{ }^{\circ} \mathrm{C}$ and $158^{\circ} \mathrm{C}$, respectively. This decrease can be explained by a further plasticizing effect of XL.

Performing the crosslinking reaction at $170{ }^{\circ} \mathrm{C}$ in the presence of an equal amount of azide and alkyne moieties leads, however, to vastly different azide conversions for $\mathbf{3 a A Z}_{\mathbf{1 5}}$ and $\mathbf{3 a}_{\mathbf{4 3}} \mathbf{A Z}_{\mathbf{1 5}}$. The azide-alkyne reaction can be followed with isothermal ATR-FTIR spectroscopy (Fig. S3 and $\mathrm{S} 4 \uparrow)$ by recording the corresponding symmetrical-stretching mode bands $\left(\mathrm{N}_{3}, 2095 \mathrm{~cm}^{-1} ; \mathrm{C} \equiv \mathrm{C}-\mathrm{H}, 3300 \mathrm{~cm}^{-1}\right)$. Fig. 2

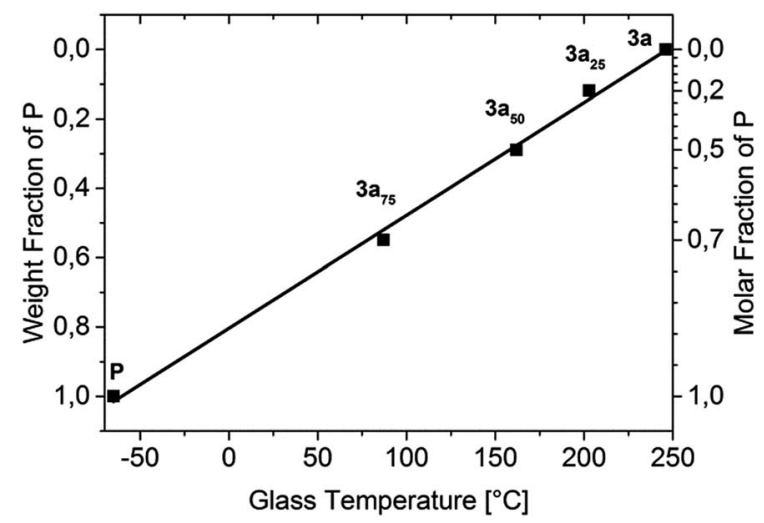

Fig. $1 T_{\mathrm{g}}$ dependence on the weight and molar fractions of $\mathrm{P}$ in the polymers $3 a_{1} 3 a_{25}, 3 a_{50}$, and $3 a_{75}$.

shows the azide-related peak areas over time during constant heating at $170{ }^{\circ} \mathrm{C}$. While the crosslinking reaction is complete (i.e., $100 \%$ azide consumption) after $35 \mathrm{~min}$ for low- $T_{\mathrm{g}}$ $\mathbf{3 a}_{\mathbf{4 3}} \mathbf{A Z}_{\mathbf{1 5}}$, the azide conversion in $\mathbf{3} \mathbf{a A Z}_{\mathbf{1 5}}$ stops after only a few minutes and $c a .75 \%$ of the azide groups remain unreacted. The latter is due to the high glass transition of $\mathbf{3 a A Z}_{\mathbf{1 5}}$ which

Table 2 Electronic and optical properties of the synthesized polymers

\begin{tabular}{|c|c|c|c|c|c|c|c|c|}
\hline Polymer & Absorption max. ${ }^{a}[\mathrm{eV}]$ & Fluorescence $\max ^{b}[\mathrm{eV}]$ & Stokes shift $[\mathrm{eV}]$ & $\mathrm{LUMO}^{c}[\mathrm{eV}]$ & $\mathrm{HOMO}^{d}[\mathrm{eV}]$ & $\operatorname{HOMO}^{e}[\mathrm{eV}]$ & $E_{\mathrm{G}}^{f}[\mathrm{eV}]$ & $E_{\mathrm{T}}{ }^{g}[\mathrm{eV}]$ \\
\hline $3 \mathbf{a}_{25}$ & 3.79 & 2.91 & 0.88 & -2.24 & -5.60 & -5.45 & 3.36 & 2.88 \\
\hline $3 a_{75}$ & 3.78 & 3.06 & 0.72 & -2.19 & -5.55 & -5.49 & 3.36 & 2.9 \\
\hline $3 \mathbf{b}$ & 4.01 & 3.05 & 0.96 & -2.18 & -5.49 & -5.47 & 3.31 & 2.9 \\
\hline $3 c$ & 4.01 & 3.09 & 0.96 & -2.19 & -5.58 & -5.45 & 3.39 & 2.9 \\
\hline $3 f$ & 3.94 & 3.02 & 0.92 & -2.17 & -5.29 & -5.24 & 3.12 & 2.81 \\
\hline
\end{tabular}

${ }^{a}$ As solid film. ${ }^{b}$ Photoluminescence spectra as solid film. ${ }^{c}$ LUMO values were calculated by using the optical bandgap and the HOMO-values from PESA measurements. ${ }^{d}$ Photoelectron spectroscopy in air (PESA). ${ }^{e}$ Cyclovoltammetry peak potential against ferrocene standard. ${ }^{f}$ Onset from UV/ Vis-spectra. ${ }^{g}$ For triplet energy levels the onsets of phosphorescence spectra were taken. 


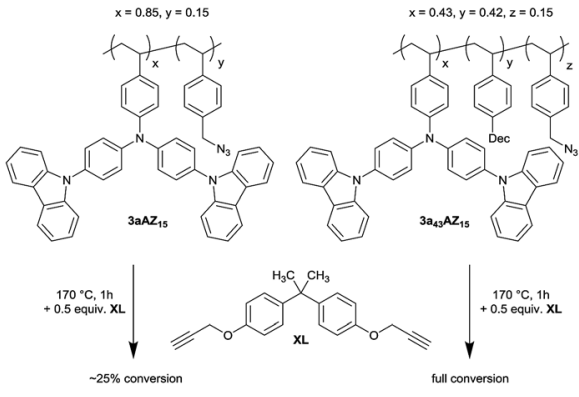

Scheme 3 Crosslinker incorporation into low and high $T_{\mathrm{g}}$ polymers.

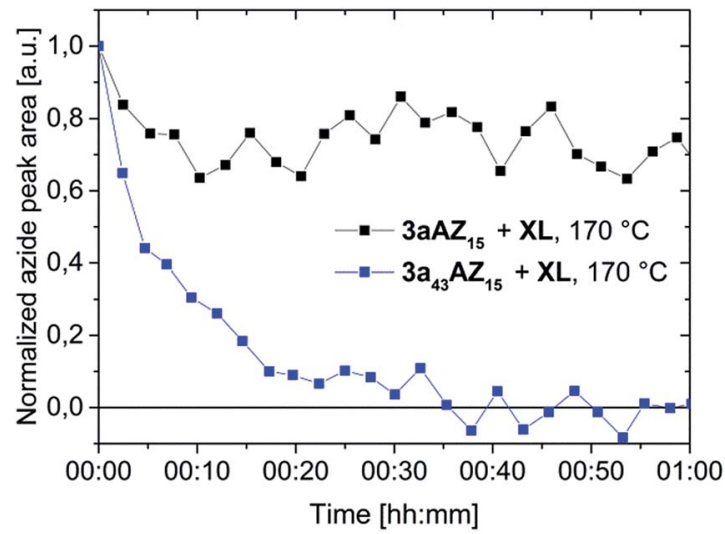

Fig. 2 Peak area isotherm of the $2095 \mathrm{~cm}^{-1}$ symmetric azide stretching at $170{ }^{\circ} \mathrm{C}$ of polymers $3 a A Z_{15}$ and $3 a_{43} A Z_{15}$ in the presence of the crosslinker $\mathrm{XL}$.

hinders the segmental movement of the crosslinker groups and therefore prevents the encounter of the reaction partners. It is thus clear that an effective crosslinking procedure must be conducted above the glass transition of the polymer, but well below the azide decomposition temperature. For $\mathbf{3 a A Z}_{15}$ (i.e., the high- $T_{\text {g }}$ polymer without plasticizers) both conditions cannot be fulfilled at the same time, which highlights exemplary the importance of glass transition tuning presented in this work.

Notice that we observe a significant $(\sim 20 \%)$ wash-off of the (partially) crosslinked $\mathbf{3 a A Z}_{\mathbf{1 5}}$ layers after rinsing with toluene (see UV-Vis absorption spectra Fig. S5 $\dagger$ ). Crosslinked $\mathbf{3 a}_{\mathbf{4}} \mathbf{A} \mathbf{Z Z}_{\mathbf{1 5}}$ layers, on the contrary, exhibit excellent solvent resistance (Fig. S6†).

\section{Simultaneous HOMO level and $T_{\mathrm{g}}$ tuning by alkoxy groups with varied alkyl lengths}

An alternative way to achieve a $T_{\mathrm{g}}$ adaption is the direct substitution of the pendant carbazole groups (Scheme 4). We decided to introduce alkoxy groups at different positions on the carbazole groups of the poly-TCTA (3a) to reduce the $T_{\mathrm{g}}$ while additionally increasing the electron density at the carbazole. The latter approach gives a viable ability to fine-tune the HOMO level of the polymer, as has been shown previously in a study on substituted molecular TAPC. ${ }^{12}$

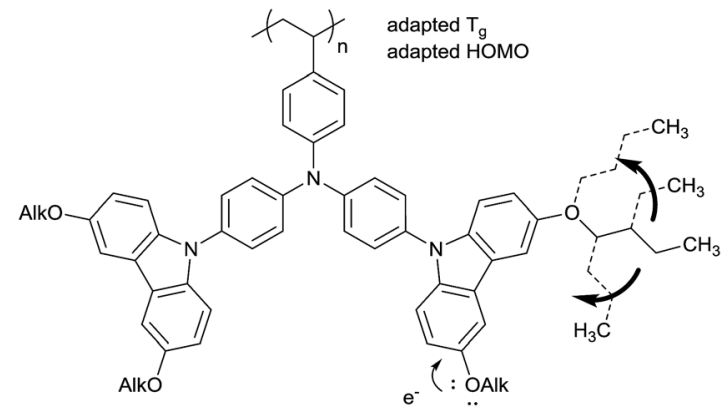

Scheme 4 The plasticizing and electronic influence of alkoxy groups on poly-TCTA.

For the alkoxy-substituted TCTA polymers (3b-f) an increasing number of alkylic carbons per pendant group were introduced. The alkoxy substitution of carbazoles $(\mathbf{b} / \mathbf{d} / \mathbf{e} / \mathbf{f}$, Scheme 5) was performed following a procedure by M. A. Keegstra et al. for the copper(I)halide catalyzed synthesis of alkyl aryl ethers ${ }^{16}$ which was applied to carbazoles before. ${ }^{17,18} 2-((2-$ Ethylhexyl)oxy)-9H-carbazole (c) was obtained by simple etherification of the aryl ether and the corresponding 2-hydroxy- $9 \mathrm{H}^{-}$ carbazole. The following reactions towards the polymers $\mathbf{3 b}-\mathbf{f}$ (top of Scheme 5) were performed according to a procedure published by Thesen et $a .^{8}{ }^{8}$ The incorporation of the alkoxy groups leads to a notable decrease of $T_{\mathrm{g}}$ (see Table 1). As compared to unsubstituted poly-TCTA, there is a minor $T_{\mathrm{g}}$ reduction of $26 \mathrm{~K}$ for polymer $3 \mathbf{b}$ with two methoxy groups, a 62 $\mathrm{K}$ decrease for polymer $3 \mathbf{e}$ with four ethoxy groups, and a decrease of $100 \mathrm{~K}$ for polymers $\mathbf{3 c}$, $\mathbf{3 d}$, and $\mathbf{3 f}$ with four butoxy or two ethylhexyloxy substituents. As a rule of thumb, each additional alkylic carbon per pendant group reduces $T_{\mathrm{g}}$ by about 7$13 \mathrm{~K}$. Polymers 3c, 3d, and $\mathbf{3 f}$ have glass transitions at around $150^{\circ} \mathrm{C}$ which we prefer for the use in OLEDs as outlined earlier.

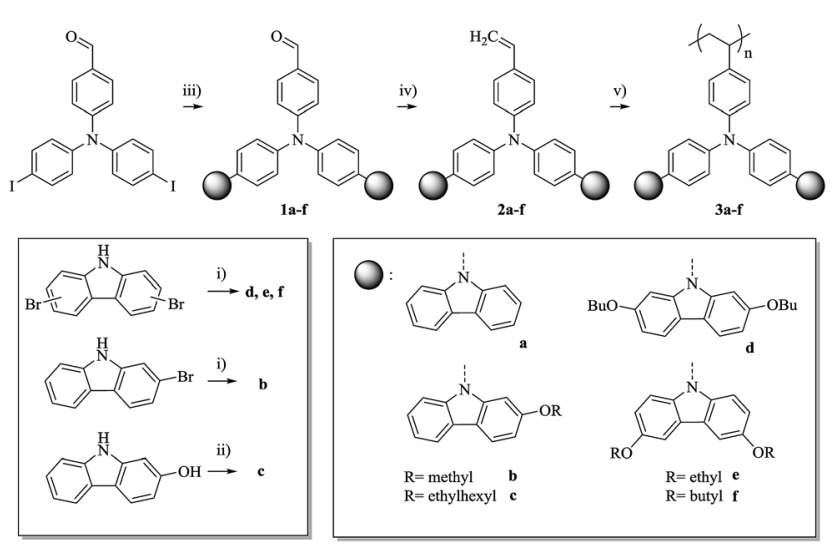

Scheme 5 Synthetic route towards $T_{\mathrm{g}}$-adapted poly-TCTA copolymers and alkoxy-substituted poly-TCTA derivatives with improved hole injection properties. (i) NaOAlk, bromo-9H-carbazole, Cul, DMF, $120{ }^{\circ} \mathrm{C}, 1-24 \mathrm{~h}$; (ii) 9H-carbazol-2-ol, 3-(bromomethyl)heptane, $\mathrm{K}_{2} \mathrm{CO}_{3}, \mathrm{DMF}, 100^{\circ} \mathrm{C}, 20 \mathrm{~h}$; (iii) a-f, Cu-bronze, $\mathrm{K}_{2} \mathrm{CO}_{3}, 18$-crown-6, o$\mathrm{DCB}, 200^{\circ} \mathrm{C}, 1 \mathrm{~h}$ to $24 \mathrm{~h}$; (iv) $1 \mathrm{a}-\mathrm{f}, \mathrm{MePPh}_{3} \mathrm{Br}, \mathrm{KO}^{t} \mathrm{Bu}, 0^{\circ} \mathrm{C}, 2 \mathrm{~h}$; (v), AIBN (2 M\%), THF (toluene for $3 f$ ), $50^{\circ} \mathrm{C}, 2 \mathrm{a}-\mathrm{f}$. 
Polymers $3 \mathbf{a}, \mathbf{3} \mathbf{a}_{25}, \mathbf{3} \mathbf{a}_{50}$, and $\mathbf{3} \mathbf{a}_{75}$ have degrees of polymerization (DP) of around 50-70 and polymers 3b-f of around 15-40 (Table 1). From our experience, the $T_{\mathrm{g}}$ values of polystyrenes substituted with bulky side groups are essentially independent of molecular weight, if DP $\geq 15$. This is supported by Claudy et $a{ }^{19}{ }^{19}$ who show that the $T_{\mathrm{g}}$ of polystyrene remains almost unchanged for polymer chains with more than 25 repeat units. The azide functionalized polymers $\mathbf{3} \mathbf{a A Z}_{\mathbf{1 5}}, \mathbf{3 a}_{\mathbf{4 3}} \mathbf{A} \mathbf{Z}_{\mathbf{1 5}}$ and $\mathbf{3} \mathbf{f} \mathbf{A Z} \mathbf{Z}_{\mathbf{1 5}}$ have similar weight distributions compared to the noncrosslinkable counterparts (Table 1).

In addition to the adaption of the glass transition, the introduction of alkoxy groups at the functional $\pi$ conjugated carbazoles allows for a tuning of the energetic states. Here, we investigate this concept by introducing substituents with varied alkyl chain lengths and varied substitution positions. HOMO level values were determined with photoelectron spectroscopy in air (PESA) and cyclovoltammetry (CV); these results are in good agreement (with a maximum deviation of $0.15 \mathrm{meV}$ for polymer $\mathbf{3 a}_{25}$ ) and are summarized in Table 2 . All polymers were reversible for several CV-measurement cycles, indicating a good electrochemical stability. The unsubstituted polymer 3a has the deepest HOMO level, followed by the polymers bearing alkoxy groups in the meta-position of the carbazole nitrogen (3b/3c/3d). Unexpectedly, the work function change for $3 \mathbf{b}$ with one methoxy group $(\Delta=0.13 \mathrm{eV}$, relative to $3 \mathrm{a}$ and according to PESA measurements) is slightly bigger than that for $\mathbf{3 c}$ (having one ethoxyhexyl group, $\Delta=0.04 \mathrm{eV}$ ) and 3d (having two butoxy groups, $\Delta=0.09 \mathrm{eV}$ ). Generally, however, the influence of metasubstituted alkoxy groups on the HOMO level is relatively small and the differences are close to the uncertainty of the PESA and $\mathrm{CV}$ measurements. A significant change of $\Delta=0.3 \mathrm{eV}$ is observed for the HOMO levels of polymers $\mathbf{3 e}$ and $\mathbf{3 f}$ which have their alkoxy substituents in para-position to the carbazolenitrogen. This can be explained by para-ring substituent effects.

Optical properties of the polymers. The absorption, normalized fluorescence and phosphorescence spectra of neat films of the investigated polymers 3a-f are shown in Fig. 3. The details of the photophysical properties of these compounds are summarized in Table 2 . The absorption spectra of the $\mathbf{3 a} / \mathbf{3} \mathbf{a}_{25-75}$ copolymers are identical for the most part except for higher oscillator strength at wavelengths smaller than $240 \mathrm{~nm}$, which is contributed to by the 1decyl-4-vinylbenzene absorption. Compounds without alkyl chains demonstrated absorption bands with peak positions at $297 \mathrm{~nm}$ and $328 \mathrm{~nm}$. In the polymers with alkyl chains attached to the carbazole at 2- and 2,7-position (3b-d) these two bands are slightly redshifted. Attaching butoxy groups to carbazole at 3,6-position (3e and 3f) redshifts those two bands to approx. $315 \mathrm{~nm}$ and $341 \mathrm{~nm}$. This effect is due to the increased $\pi$-conjugated pendent systems arising from the electron donating ability of methoxy/ butoxy groups. ${ }^{20,21}$ A similar situation was observed in fluorescence spectra. Polymers $\mathbf{3} \mathbf{a}-\mathbf{3} \mathbf{a}_{\mathbf{7 5}}$ exhibited broad emission with a peak at $400 \mathrm{~nm}$. Substituents at 2- and 2,7-position do not change the peak position of the spectra, but the shape of spectra become more narrow. The fluorescence spectra of $\mathbf{3 e}$ and $\mathbf{3 f}$ show a redshift of about $10 \mathrm{~nm}$, similar as in their absorption spectra. Polymer $\mathbf{3 f}$ did however exhibit a fluorescence spectrum with a more pronounced shoulder at longer wavelengths.

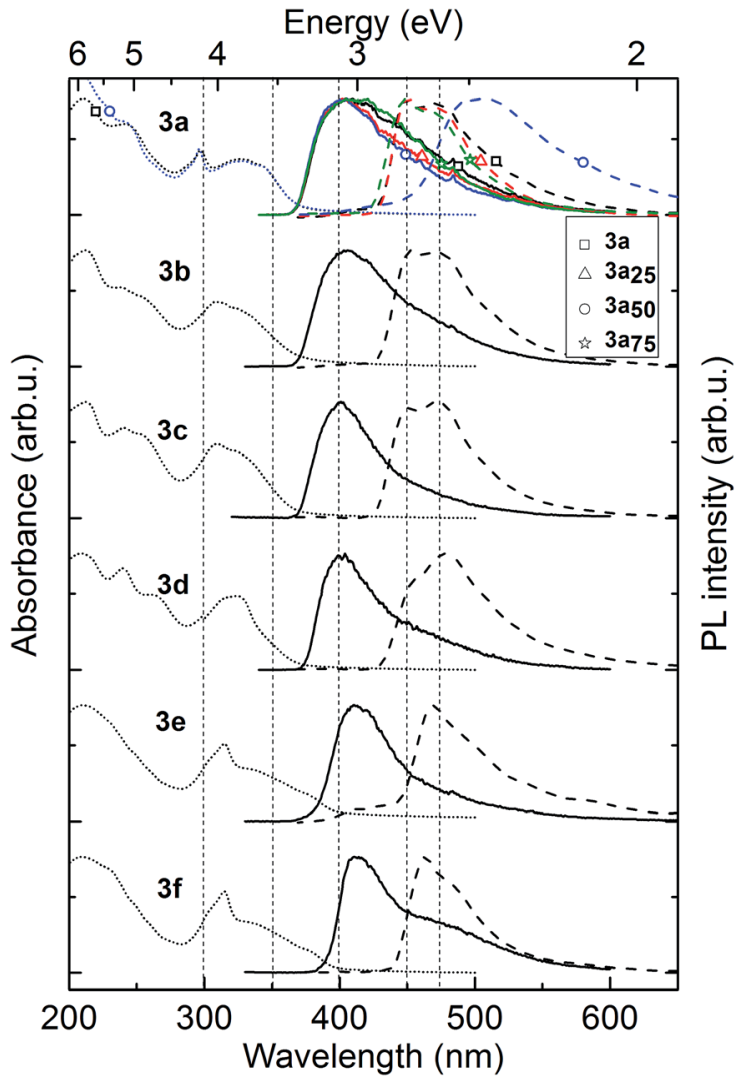

Fig. 3 UV/Vis (dotted lines) and photoluminescence (PL) spectra (straight lines) and phosphorescence (dashed lines) of the polymers $3 a-f$. The top-graph shows additionally the spectra of $3 a_{25}$ (triangle), $3 a_{50}$ (circle) and $3 a_{75}$ (star) for comparison.

The phosphorescence spectra of each material act in a similar fashion to fluorescence. 3a-d demonstrate small changes in phosphorescence spectra, the spectra of polymers $\mathbf{3 e}$ and $\mathbf{3 f}$ are redshifted by $10 \mathrm{~nm}$. Polymer $3 \mathbf{e}$ is the only material showing a small delayed fluorescence signal which might indicate enhanced triplet mobility or higher ISC yield. Most importantly, all polymers have a high triplet energy (2.8-2.9 eV, see Table 2) which is compatible with their use as host or hole-transporting material in OLEDs with green-to-blue phosphorescent emitters.

The various substituents on the polymers have very little effect on the triplet energy, as desired. However, polymer $\mathbf{3} \mathbf{a}_{50}$ containing $50 \mathrm{M} \%$ of 1-decyl-4-vinylbenzene spacer demonstrated very broad, structureless and redshifted, by $50 \mathrm{~nm}$, phosphorescence. This we ascribe to emission from triplet states dimers, formed between interacting neighbouring carbazole units, as was previously observed in PVK. ${ }^{22}$

Electrical characteristics of the polymers. The electrical characteristics of the substituted TCTA-based polymers have been tested in a hole-only current diode geometry (see inset of Fig. 4) with similar polymer layer thicknesses. In these devices, positive charge carriers can be injected from the ITO/PEDOT:PSS anode into the polymer layer. The Al cathode provides an electron- and hole-injection blocking contact. In Fig. 4, clear diode behaviors with a forward (at positive voltages) and a blocking (at negative voltages) direction are evident. The characteristics show 


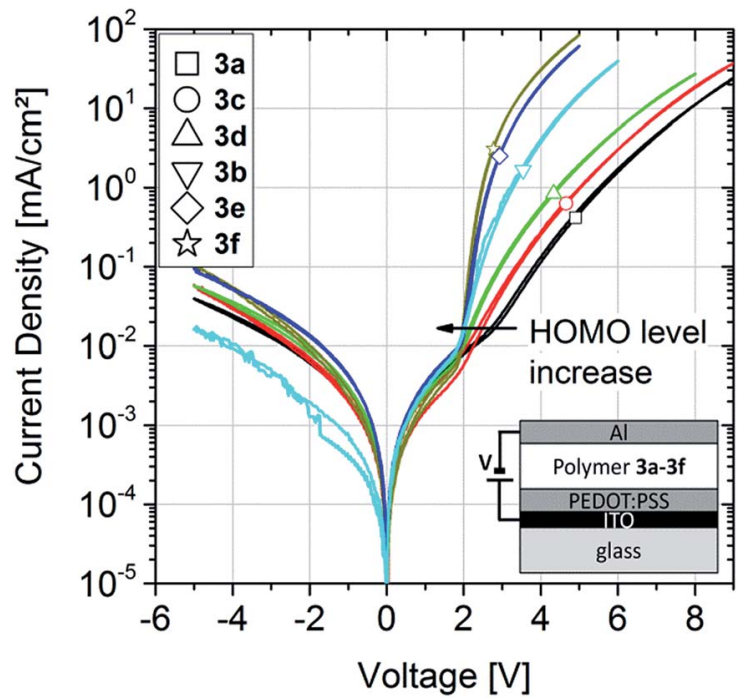

Fig. 4 Electrical characteristics of hole-only diodes prepared from polymers $3 a-f$. Positive voltages refer to the injection of holes from the ITO contact into the polymer layer. The polymer layers have similar thicknesses of $80-100 \mathrm{~nm}$. Inset: sample structure of the hole-only diodes.

a steep current rise above a certain onset voltage (2-2.5 V), which shows that the polymers allow for hole transport. The onset voltages clearly correlate with the HOMO level of the polymers; i.e., the deeper the HOMO level (see Table 1), the larger the onset voltage. This shows that all hole-only characteristics in Fig. 4 suffer from an injection barrier which is largely determined by the HOMO level of the respective polymer. Consequently, it is not possible to extract charge carrier mobilities from these measurements. Note, however, that the current rise beyond the onset voltage is much steeper for the polymers with four alkoxy substituents in para-position (polymers $\mathbf{3 e}$ and $\mathbf{3 f}$ ) than for the respective polymer with these groups in meta-position, which points to a larger mobility of the former set of polymers.

In order to represent the full span of the HOMO level range which is accessible with the new TCTA-based polymers, we tested the crosslinkable versions of $\mathbf{3 a}$ (unsubstituted poly-TCTA with $15 \mathrm{M} \%$ azide content, $\mathbf{3 a}_{\mathbf{4 3}} \mathbf{A Z}_{\mathbf{1 5}}$ ) and $\mathbf{3 f}$ (poly-3,6-(BuO) $)_{4}$ TCTA with $15 \mathbf{M} \%$ azide content, $\mathbf{3} \mathbf{f A Z}_{\mathbf{1 5}}$ ) as hole-transport layers in fully solution-processed OLEDs (i.e., solution-processing except for the electrodes). Notice that in the case of unsubstituted poly-TCTA, we have used the low- $T_{\mathrm{g}}$ variant with decyl styrene plasticizer in order to allow for crosslinking well below $200{ }^{\circ} \mathrm{C}$.

15-20 $\mathrm{nm}$ thick hole-transport layers were fabricated by spincoating from toluene solutions on top of ITO/PEDOT:PSS patterned electrodes. Crosslinking of these layers was performed by heating at $170{ }^{\circ} \mathrm{C}$ for $40 \mathrm{~min}$. The emission layer is a ternary blend consisting of an iridium-based phosphorescent green emitter, a co-host, and an electron transporting polymer as is described in our previous work, ref. 23 and 24 The emission layer was annealed at $180^{\circ} \mathrm{C}$ for $30 \mathrm{~min}$. The $\mathrm{Ba} / \mathrm{Ag}$ cathode was deposited by subsequent evaporation. Further details of the sample preparation can be found in the ESI. $\dagger$
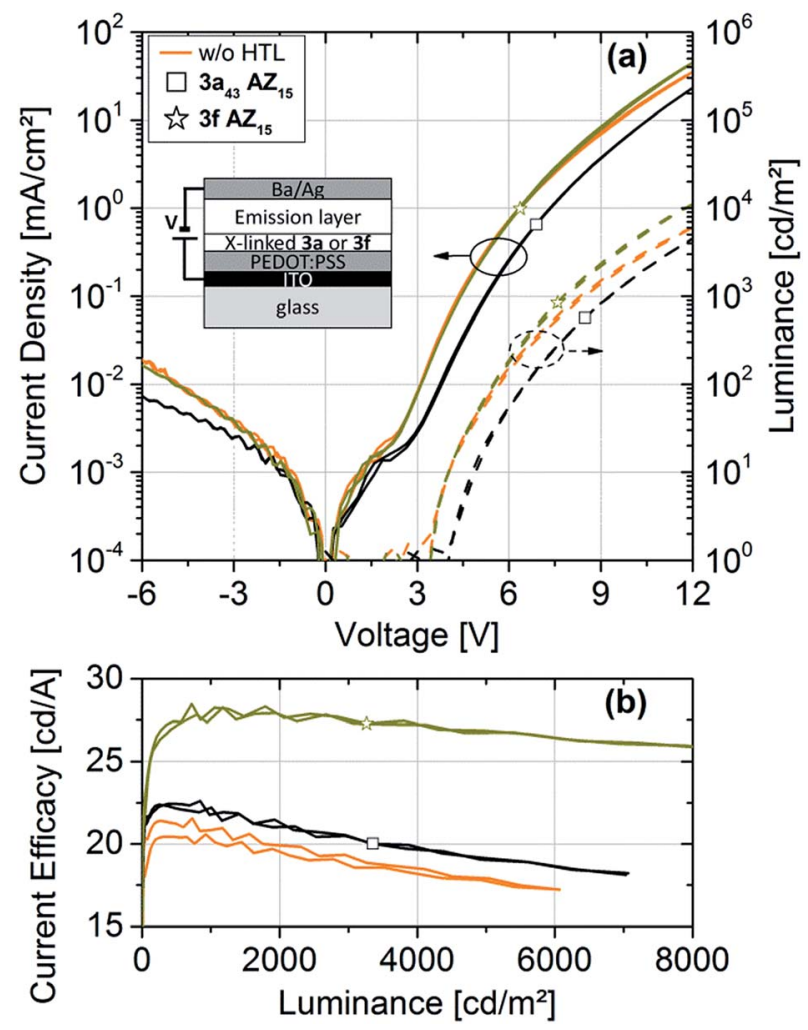

Fig. 5 (a) $j-L-V$ characteristics and (b) current efficacies of OLEDs with and without hole-transport layers based on the crosslinkable polymers $3 a$ or $3 c$ with incorporated azide (AZ) moieties.

The OLED characteristics are shown in Fig. 5a. Clear diode behaviors and high rectification ratios are observed. Comparing the devices with $\mathbf{3} \mathbf{f} \mathbf{A Z} \mathbf{Z}_{\mathbf{1 5}}$ and with $\mathbf{3 a}_{\mathbf{4 3}} \mathbf{A} \mathbf{Z}_{\mathbf{1 5}}$ HTL, the current and luminance onset voltage is increased for the latter sample due to the deep HOMO level of $\mathbf{3 a}_{\mathbf{4 3}} \mathbf{A} \mathbf{Z}_{\mathbf{1 5}}$, as expected.

Fig. 5b shows the current efficacies of the devices with and without HTL. It can be clearly seen that the use of a HTL, separating the emission layer from the anode, leads to an efficacy increase as compared to devices with no HTL. The highest current efficacy is exhibited by the device with $\mathbf{3 f A Z}_{\mathbf{1 5}}$ HTL, which is probably due to the proper adaption of its HOMO level to the energetic landscape of the emissive layer. ${ }^{24}$ We cannot determine the detailed physical role that the HTL plays in our devices within the scope of this article; however, it seems plausible that the high triplet energies and the high-lying LUMO-derived states of the TCTA-based polymers serve for a blocking of triplets and electrons, such that those species become confined to the emission layer. Most importantly, we have shown that both crosslinkable TCTA-based polymers are suitable and advantageous to be used as HTL materials in OLEDs as they enable the subsequent solution-processing of the emission layer without any re-dissolution.

\section{Conclusions}

We have demonstrated two approaches to adapt functional side-chain polystyrenes towards the needs of a solution- 
processed multilayer OLED structure: by introduction of plasticizers as co-monomers or as substituents to the $\pi$-conjugated units of the prototypical hole-transporting TCTA side-chain polystyrene, the glass transition can be tuned in a wide range between 87 and $245{ }^{\circ} \mathrm{C}$. This is of particular importance for thermal crosslinking reactions, where the reaction temperature should be far lower than $200{ }^{\circ} \mathrm{C}$ in order to enable a costefficient, complete process and to avoid decomposition of the reactants. With the moderate glass transitions of the new polyTCTAs at around $150{ }^{\circ} \mathrm{C}$ high conversions can be achieved upon thermally initiated crosslinking, which is demonstrated on crosslinkable polymers containing an azide-alkyne crosslinker.

Moreover, the approach of substituting the TCTA core with alkoxy groups allows for a concomitant tuning of the HOMO level, which is desired for the application of these polymers as hole transport layers in OLED structures. While the HOMO level can be adjusted to values between -5.29 and $-5.62 \mathrm{eV}$, the high LUMO level position and the high triplet energy of poly-TCTA are maintained. These properties render the crosslinkable, substituted poly-TCTA variants ideal to be used as holetransport electron-blocking layer between the anode and the emission zone of green phosphorescent OLEDs, as we have demonstrated for solution-processed devices.

\section{Acknowledgements}

F. R. P. Limberg, P. Pingel, S. Janietz, and H. Krüger acknowledge funding by the German BMBF (ENAB-SPOLED 13N23634).

\section{References}

1 B. Zhang, L. Liu and Z. Xie, Isr. J. Chem., 2014, 54, 897-917. 2 W. Li, J. Li and M. Wang, Isr. J. Chem., 2014, 54, 867-884.

3 S. Sax, N. Rugen-Penkalla, A. Neuhold, S. Schuh, E. Zojer, E. J. W. List and K. Müllen, Adv. Mater., 2010, 22, 2087-2091.

4 C. W. Joo, S. O. Jeon, K. S. Yook and J. Y. Lee, Org. Electron., 2009, 10, 372-375.

5 C. A. Zuniga, S. Barlow and S. R. Marder, Chem. Mater., 2011, 23, 658-681.

6 G. Liaptsis, D. Hertel and K. Meerholz, Angew. Chem., 2013, 125, 9742-9746.

7 M.-H. Wu, J.-H. Lee, M.-K. Leung, C.-C. Liao and Y. Chang, Proc. SPIE 5519, Organic Light-Emitting Materials and Devices VIII, ed. Z. H. Kafafi and P. A. Lane, 2004, vol. 263, DOI: 10.1117/12.559561.
8 M. W. Thesen, B. Höfer, M. Debeaux, S. Janietz, A. Wedel, A. Köhler, H.-H. Johannes and H. Krueger, J. Polym. Sci., Part A: Polym. Chem., 2010, 48, 3417-3430.

9 X. Gong, S.-H. Lim, J. C. Ostrowski, D. Moses, C. J. Bardeen and G. C. Bazan, J. Appl. Phys., 2004, 95, 948-953.

10 S. Tokito, M. Suzuki, F. Sato, M. Kamachi and K. Shirane, Org. Electron., 2003, 4, 105-111.

11 G. Greczynski, T. Kugler, M. Keil, W. Osikowicz, M. Fahlman and W. R. Salaneck, J. Electron Spectrosc. Relat. Phenom., 2001, 121, 1-17.

12 G. Liaptsis and K. Meerholz, Adv. Funct. Mater., 2013, 23, 359-365.

13 C. G. Overberger, C. Frazier, J. Mandelman and H. F. Smith, J. Am. Chem. Soc., 1953, 75, 3326-3330.

14 J. M. Spruell, M. Wolffs, F. A. Leibfarth, B. C. Stahl, J. Heo, L. A. Connal, J. Hu and C. J. Hawker, J. Am. Chem. Soc., 2011, 133, 16698-16706.

15 R.-Q. Png, P.-J. Chia, J.-C. Tang, B. Liu, S. Sivaramakrishnan, M. Zhou, S.-H. Khong, H. S. O. Chan, J. H. Burroughes, L.-L. Chua, R. H. Friend and P. K. H. Ho, Nat. Mater., 2010, 9, 152-158.

16 M. A. Keegstra, T. H. A. Peters and L. Brandsma, Tetrahedron, 1992, 48, 3633-3652.

17 Y. Kikugawa, Y. Aoki and T. Sakamoto, J. Org. Chem., 2001, 66, 8612-8615.

18 B. Schmidt, S. Krehl, A. Kelling and U. Schilde, J. Org. Chem., 2012, 77, 2360-2367.

19 P. Claudy, J. M. Létoffé, Y. Camberlain and J. P. Pascault, Polym. Bull., 1983, 9, 208-215.

20 D. Gudeika, J. V. Grazulevicius, G. Sini, A. Bucinskas, V. Jankauskas, A. Miasojedovas and S. Jursenas, Dyes Pigm., 2014, 58-70, DOI: 10.1016/j.dyepig.2014.02.023.

21 A. Tomkeviciene, J. V. Grazulevicius, K. Kazlauskas, A. Gruodis, S. Jursenas, T. H. Ke and C. C. Wu, J. Phys. Chem. C, 2011, 4887-4897, DOI: 10.1021/jp111333v.

22 V. Jankus and A. P. Monkman, Adv. Funct. Mater., 2011, 21, 3350-3356.

23 B. C. D. Salert, A. Wedel, L. Grubert, T. Eberle, R. Anémian and H. Krueger, Adv. Mater. Sci. Eng., 2012, 2012, 1-15.

24 B. C. D. Salert, H. Krueger, S. A. Bagnich, T. Unger, F. Jaiser, M. Al-Sa'di, D. Neher, A. Hayer and T. Eberle, J. Polym. Sci., Part A: Polym. Chem., 2013, 51, 601-613. 